\title{
Cost-minimisation analysis comparing gemcitabine/cisplatin, paclitaxel/carboplatin and vinorelbine/cisplatin in the treatment of advanced non-small cell lung cancer in Italy
}

\author{
S. Novello ${ }^{\text {a }}$ A. Kielhorn ${ }^{b, *}$, G. Stynes ${ }^{c}$, G. Selvaggi a, F. De Marinis ${ }^{\text {, }}$, \\ A. Maestri ${ }^{e}$, P. Foggi ${ }^{f}$, D. Tilden ${ }^{c}, M$. Tonato ${ }^{g}$, L. Crinò ${ }^{e}$, M. Rinaldi ${ }^{f}$, \\ A.M. Migliorino ${ }^{d}$, G.V. Scagliotti ${ }^{a}$, on behalf of the Italian Lung Cancer \\ Project Investigators
}

\author{
a Department of Clinical and Biological Sciences, University of Torino, Turin, Italy \\ ${ }^{b}$ European Health Outcomes Research, Eli Lilly and Co. Ltd, Erl Wood Manor, Sunninghill Road, \\ Windlesham, Surrey GU20 6PH, UK \\ ' M-TAG UK Ltd, London, UK \\ d Division of Pneumo-Oncology, Forlanini Hospital, Rome, Italy \\ e Division of Medical Oncology, Bellaria Hospital, Bologna, Italy \\ ${ }^{f}$ Division of Medical Oncology B, Regina Elena Institute, Rome, Italy \\ s Division of Medical Oncology, Policlinico Hospital, Perugia, Italy
}

Received 14 July 2004; received in revised form 15 November 2004; accepted 17 November 2004

\section{KEYWORDS}

Chemotherapy;

Gemcitabine;

Paclitaxel;

Vinorelbine;

Non-small cell lung

cancer;

Cost-minimisation;

Pharmacoeconomics
Summary A retrospective cost-minimisation analysis was conducted comparing novel chemotherapies for the treatment of chemo-naive patients with locally advanced, recurrent, and/or metastatic non-small cell lung cancer (NSCLC). Resource use information was obtained from a Phase III randomised trial investigating the efficacy and toxicity of gemcitabine/cisplatin (Gem/Cis), paclitaxel/carboplatin (Pac/Carbo) and vinorelbine/cisplatin (Vin/Cis) combination regimens in 612 patients with advanced NSCLC. Since there were no statistically significant differences between the three treatments in terms of progression-free or overall survival in this trial, a cost-minimisation analysis was considered to be the appropriate type of economic evaluation. The perspective was that of the national

\footnotetext{
* Corresponding author. Tel.: +44 1276 484132; fax: +44 1276483192.

E-mail address: kielhorn_adrian@lilly.com (A. Kielhorn).
} 
healthcare provider in Italy. Medical resource use was obtained from the clinical trial database, from which mean cost streams were calculated for each treatment group. The mean total treatment costs per patient were $€ 8094, € 11,203$ and $€ 9320$ for the Gem/Cis, Pac/Carbo and Vin/Cis regimens, respectively. Based on resource consumption in a clinical trial, Gem/Cis had the lowest overall mean costs of the three chemotherapy regimens. Gem/Cis therefore has the potential to save costs in the treatment of advanced NSCLC in Italy.

(C) 2005 Elsevier Ireland Ltd. All rights reserved.

\section{Introduction}

Lung cancer remains the leading cause of cancerrelated death in Europe and North America, accounting for nearly $30 \%$ of all cancer deaths [1]. Approximately $80 \%$ of all lung cancers are non-small cell lung cancer (NSCLC), and more than $70 \%$ of patients with NSCLC present with locally advanced or metastatic disease $[2,3]$. The prognosis for patients with NSCLC remains poor: approximately $80 \%$ of patients die within 1 year of diagnosis, and the 5-year survival rate is estimated at $14 \%$ in the USA and $8 \%$ in Europe [4].

Currently, cisplatin-based regimens are considered the standard treatment for advanced NSCLC, but the proportion of patients with advanced NSCLC receiving chemotherapy varies widely across countries [5]. Chemotherapy prolongs survival and palliates tumour-related symptoms [6,7], and has been shown to be cost-effective [1].

New chemotherapeutic agents such as gemcitabine, paclitaxel and vinorelbine have been extensively tested in chemo-naive patients with NSCLC, and randomised clinical trials have demonstrated the activity of these new agents alone or in combination with platinum derivatives for the treatment of locally advanced and metastatic NSCLC [8-16]. However, comparative studies have failed to demonstrate the superiority of any one of these so-called third-generation agents over the others in terms of improved tumour response rate or survival, although they do have different toxicity profiles $[3,8,9,17]$.

Given the similarity in the effectiveness of combination chemotherapy regimens, decisions regarding treatment for advanced NSCLC should take into account the toxicity profiles, convenience and costs. Healthcare utilisation data are beginning to be collected prospectively during clinical trials of chemotherapeutic regimens so that economic analyses can be performed.

Gemcitabine has already undergone extensive economic evaluation, and been shown to be cost-effective when used alone or in combination with cisplatin for treating advanced NSCLC
$[5,18]$. The aim of the present study was to compare the mean costs of three chemotherapy regimens - gemcitabine/cisplatin (Gem/Cis), paclitaxel/carboplatin (Pac/Carbo) and vinorelbine/cisplatin (Vin/Cis) - in the treatment of chemotherapy-naive patients with locally advanced, recurrent and/or metastatic NSCLC in Italy, using resource utilisation data from a phase III randomised clinical trial [9].

\section{Methods}

\subsection{Patients and treatments}

Resource utilisation data for the economic analysis were collected prospectively during a phase III randomised trial conducted in 41 centres in Italy, which compared Gem/Cis, Pac/Carbo and Vin/Cis in 612 chemotherapy-naive patients with locally advanced (stage IIIB) and/or metastatic (stage IV) NSCLC [9]. The median age of the patients was 63 years, approximately $78 \%$ were male, the majority (92\%) had Eastern Cooperative Performance Group (ECOG) performance status $0-1$, and $81 \%$ had stage IV disease.

Of the 612 patients enrolled, 607 were randomised to receive either Gem/Cis $(n=205)$, $\mathrm{Pac} /$ Carbo $(n=201)$ or Vin/Cis $(n=201)$. The doses and treatment schedules are summarised in Table 1. Total drug dose was based on a mean body surface area of $1.8 \mathrm{~m}^{2}$ per patient. Patients who reached stable disease received a maximum of six cycles of therapy, whereas patients who demonstrated an objective response (complete or partial) could receive up to eight cycles. Dose adjustments within a cycle were made on the basis of haematological and nonhaematological toxicities as specified in the protocol [9].

The primary endpoint of the trial was overall response rate, and the study was sufficiently powered to detect a $15 \%$ difference in the overall response rate between the Gem/Cis or Pac/Carbo arms and the $\mathrm{Vin} / \mathrm{Cis}$ arm. Time to disease progression and overall survival were secondary endpoints. 
Table 1 Dosage and treatment schedules for the chemotherapy regimens

\begin{tabular}{ll}
\hline Gem/Cis $(n=205)$ & 21-day cycle \\
& Gemcitabine: $1250 \mathrm{mg} / \mathrm{m}^{2}$, two \\
& doses per cycle $($ days 1 and 8$)$ \\
& Cisplatin: $75 \mathrm{mg} / \mathrm{m}^{2}$, one dose \\
& per cycle $($ day 2$)$ \\
& Mean cycles per patient $=4.02$ \\
Pac/Carbo $(n=201)$ & 21-day cycle \\
& Paclitaxel: $225 \mathrm{mg} / \mathrm{m}^{2}$, one \\
& dose per cycle $($ day 1$)$ \\
& Carboplatin: $400 \mathrm{mg} / \mathrm{m}^{2}$ (AUC \\
& $6 \mathrm{mg} / \mathrm{mL} / \mathrm{min}$ Calvert's \\
& formula), one dose per cycle \\
& (day 1$)$ \\
& Mean cycles per patient $=4.23$ \\
& 28-day cycle \\
Vin/Cis $(n=201)$ & Vinorelbine: $25 \mathrm{mg} / \mathrm{m}^{2}$, four \\
& doses per cycle $($ days $1,8,15$ \\
& and 22) \\
& Cisplatin: $100 \mathrm{mg} / \mathrm{m}^{2}$, one dose \\
& per cycle $($ day 1$)$ \\
& Mean cycles per patient $=3.25$ \\
\hline
\end{tabular}

\subsection{Treatment-related costs}

The economic analysis was based on the intentionto-treat population in the clinical trial. Direct healthcare costs were identified for each regimen, using the following categories: (1) chemotherapy acquisition costs (third-generation agent and platinum agent); (2) chemotherapy administration costs; (3) hospitalisation costs associated with adverse events; (4) costs of other medical resources (e.g. radiotherapy, blood transfusions, non-protocoled laboratory blood tests, concomitant medications).

Chemotherapy acquisition costs were determined by multiplying the expected chemotherapy cost per cycle by the mean number of cycles administered. The protocol-specified chemotherapy dose was used for this calculation. Chemotherapy administration costs per patient were determined by multiplying the expected number of administration days by the unit cost per drug administration day (all chemotherapy administrations were assumed to be outpatient). The number of administration days was calculated by multiplying the number of administration days per cycle by the mean number of cycles per patient.

The costs of hospitalisations due to adverse events were determined according to the proportions of patients suffering an event in the clinical trial, and the proportion of those patients who were then hospitalised for treatment of that event. The hospitalisation cost per patient was calculated as follows:

$H_{\mathrm{C}}=\sum P_{\mathrm{AE}} \times P_{\mathrm{H}} \times C$

where $H_{C}$ is the mean hospitalisation cost, $P_{\mathrm{AE}}$ the probability of suffering each adverse event, $P_{H}$ the probability of being hospitalised for that event, and $C$ the unit cost of a hospitalised episode; $\sum$ represents the fact that costs are summed across all adverse events reported in the clinical trial.

Hospitalisation costs associated with adverse events were calculated for grade $3 / 4$ febrile neutropenia, thrombocytopenia, anaemia, vomiting, neutropenia, renal failure, and grade $2 / 3$ neuropathy. The probability of being hospitalised for one of these events was $100 \%$, with the exception of grade $3 / 4$ thrombocytopenia (9\%). These probabilities were derived from consultation with clinical experts and study of the trial datasets.

Finally, the costs of other medical resources (radiotherapy, blood transfusions, non-protocoled laboratory blood tests, concomitant medications) were determined by multiplying the expected cost per patient by the proportion of patients requiring the intervention. Since data on radiotherapy use were not available from the trial, the percentage of patients requiring radiotherapy was assumed to be the same for each treatment group and was based on that reported by Comella et al. [10] for Gem/Cis (23.33\%). All medications used concomitantly with chemotherapy in the clinical trial were grouped according to chemical/therapeutic class, and a representative drug and corresponding defined daily dose for each category was found. Calculations of days of therapy in each category were based on product information, prescriptive information provided in the trial protocol and data drawn from the trial records detailing the type and duration of concomitant medication therapy for each patient.

Protocol-driven laboratory tests were excluded from the analysis. The per-patient cost of other laboratory tests was calculated by multiplying the probability of requiring tests by the mean number of tests by the mean cost of a test. The mean cost of a laboratory test was the sum of the cost of blood sampling plus the mean cost of different types of laboratory tests administered in the trial (weighted by frequency). For costing blood transfusions, both packed red blood cell and platelet outpatient transfusions were counted.

Resource use was collected from the clinical trial when available. When resource use data were not available from the trial, data were derived from product information or other published literature.

Unit costs of medical resources in Italy were derived from official published sources, including FEDERFARMA, May 2003 [19], the Italian Ministry of 
Health (Ministero della Sanità) [20] and published literature [21-23]. All unit costs are expressed in 2003 Euros $(€)$.

The mean total treatment cost per patient for each regimen was calculated as the cost of the stream of resources utilised across all patients randomised to treatment in that arm.

\subsection{Cost-minimisation analysis}

The cost-minimisation analysis was based on the clinical effectiveness results reported by Scagliotti et al. [9] and the cost estimates derived in this study using the methods described above.

One-way sensitivity analyses were performed to quantify the effects of various cost drivers in the analysis. All resource unit costs, except study medications, were varied in both directions by $10 \%$, and the associated mean costs per patient were recorded. Similar sensitivity analyses were performed for hospitalisation rates: costs and costeffectiveness were estimated in a scenario where the rates of hospitalisation were $9 \%$ (the base-case assumption for thrombocytopenic episodes) for all types of adverse events. Costs were also estimated in the scenario where $100 \%$ of thrombocytopenic episodes were hospitalised. Finally, the sensitivity analysis looked at a practical adjustment to the dosing regimen of $\mathrm{Gem} / \mathrm{C}$ is in which cisplatin is given together with gemcitabine on the first day of a cycle.

\section{Results}

\subsection{Clinical outcomes}

The efficacy and safety results of the clinical trial have been published in detail elsewhere [9], but the relevant clinical outcomes are summarised in Table 2. Median survival times (range 9.5-10 months), overall response rates (range $30-32 \%$ ) and median time to progression (range 4.6-5.5 months) were comparable in all three treatment groups. The lack of significant differences confirms the applicability of our cost-minimisation analysis.

\subsection{Treatment-related costs}

The medical resource utilisation and unit costs based on the clinical trial and other published data are listed in Table 3.

Patients treated with $\mathrm{Gem} / \mathrm{C}$ is had lower total treatment costs $(€ 8094)$ than those treated with $\mathrm{Pac} /$ Carbo $(€ 11,203)$ or Vin/Cis (€9320) (Fig. 1). Chemotherapy acquisition was a major cost factor across all regimens, ranging from $€ 1461$ for $\mathrm{Vin} / \mathrm{C}$ is to $€ 6615$ for Pac/Carbo. The cost of hospitalisation for adverse events was greatest in patients treated with $\mathrm{Vin} / \mathrm{Cis}(€ 4537)$, as were the costs of other medical resources $(€ 2493)$.

The cost difference between the $\mathrm{Gem} / \mathrm{C}$ is and Pac/Carbo regimens ( $€ 3109$ per patient) was mainly due to the much higher acquisition cost of chemotherapy for the Pac/Carbo regimen, despite the lower costs for drug administration and other medical resources (Fig. 2a). The mean cost saving associated with Gem/Cis compared with Vin/Cis was $€ 1226$ per patient. The cost difference was primarily due to the lower costs of hospitalisations associated with $\mathrm{Gem} / \mathrm{Cis}$, despite the higher cost of chemotherapy acquisition (Fig. 2b).

\subsection{Sensitivity analysis}

The results of the various scenarios confirm the main findings of the cost-minimisation analysis

Table 2 Clinical outcomes for each treatment group [9]

\begin{tabular}{llll}
\hline & Gem/Cis $(n=205)$ & Pac/Carbo $(n=201)$ & Vin/Cis $(n=201)$ \\
\hline Response rates (\% of patients) & 0 & 0.5 & 0.5 \\
$\quad$ Complete response & 30 & 31 & 30 \\
$\quad$ Partial response & 40 & 37 & 31 \\
$\quad$ Stable disease & 18 & 18 & 17 \\
$\quad$ Progressive disease & 13 & 14 & 23 \\
$\quad$ Not determinable & $30(24-37)$ & $32(25-38)$ & $30(24-36)$ \\
Overall response rate (\% of patients $(95 \% \mathrm{CI}))$ & & & \\
Survival & $9.8(8.6-11.2)$ & $10.0(9.0-12.5)$ & $9.5(8.3-11.0)$ \\
$\quad$ Median (months $(95 \% \mathrm{CI}))$ & 37 & 43 & 37 \\
$\quad$ 1-year (\% surviving) & $5.3(4.4-6.3)$ & $5.5(4.6-6.4)$ & $4.6(3.9-5.6)$ \\
\hline Median time to progression (months $(95 \% \mathrm{CI}))$ & &
\end{tabular}

$\mathrm{Cl}$ : confidence interval. 
Table 3 Medical resource utilisation for each treatment group and unit costs

\begin{tabular}{|c|c|c|c|c|}
\hline Medical resource & Gem/Cis & $\mathrm{Pac} / \mathrm{Carbo}$ & $\operatorname{Vin} / \mathrm{Cis}$ & Unit cost $(€)$ \\
\hline \multicolumn{5}{|c|}{ Drug administration (administration days per patient) } \\
\hline Outpatient & 12.1 & 4.2 & 13.0 & 63.72 \\
\hline Inpatient & 0 & 0 & 0 & 389.67 \\
\hline \multicolumn{5}{|l|}{ Hospitalisations (\% patients) } \\
\hline Febrile neutropenia & 0.5 & 1.0 & 3.0 & 2910.23 \\
\hline Thrombocytopenia & 3.3 & 0.7 & 0.05 & 4790.65 \\
\hline Vomiting & 6.6 & 0.5 & 12.6 & 2492.00 \\
\hline Neuropathy & 4.0 & 29.8 & 7.0 & 3253.00 \\
\hline Anaemia & 17.7 & 6.1 & 19.2 & 3393.64 \\
\hline Neutropenia & 38.1 & 50.3 & 64.6 & 2910.23 \\
\hline Renal failure & 0.5 & 0 & 5.0 & $27,481.17^{a}$ \\
\hline \multicolumn{5}{|l|}{ Other medical resources } \\
\hline Radiotherapy (\% patients) & 23.3 & 23.3 & 23.3 & 2845.00 \\
\hline $\begin{array}{l}\text { Packed red blood cell transfusion } \\
\text { (\% patients) }\end{array}$ & 10.7 & 4.5 & 13.4 & 103.25 \\
\hline Platelet transfusion (\% patients) & 2.4 & 0 & 0 & 21.24 \\
\hline Laboratory tests (\% patients) & 22.0 & 5.5 & 19.4 & \\
\hline Average no. of tests performed per patient & 2.9 & 3.8 & 3.1 & 4.02 \\
\hline \multicolumn{5}{|l|}{ Concomitant medications (units per patient) } \\
\hline Dexamethasone & 38.6 & 14.0 & 48.5 & 0.07 \\
\hline Ranitidine & 5.9 & 7.6 & 8.8 & 3.38 \\
\hline Ondansetron & 44.2 & 31.1 & 43.8 & 14.75 \\
\hline Furosemide & 2.0 & 4.2 & 2.1 & 0.06 \\
\hline Pheniramine maleate & 12.4 & 27.0 & 6.2 & 0.31 \\
\hline Ciprofloxacin & 5.1 & 3.7 & 4.7 & 2.93 \\
\hline Filgrastim & 0.6 & 1.4 & 2.3 & 141.77 \\
\hline Erythropoietin & 3.3 & 1.0 & 3.8 & 180.66 \\
\hline Tramadol & 10.4 & 4.3 & 6.0 & 0.76 \\
\hline Ketorolac trometamol & 12.9 & 6.5 & 7.5 & 1.04 \\
\hline Heparin & 4.2 & 3.7 & 9.4 & 10.9 \\
\hline Betamethasone phosphate & 22.9 & 22.2 & 5.1 & 0.09 \\
\hline \multicolumn{5}{|l|}{ Chemotherapy } \\
\hline \multicolumn{5}{|l|}{ Platinum agent (vials required per patient) } \\
\hline $450 \mathrm{mg}$ vials & 0 & 4.23 & 0 & 195.82 \\
\hline $50 \mathrm{mg}$ vials & 8.04 & 25.38 & 9.75 & $\begin{array}{l}18.02 \text { (Cis); } \\
21.59 \text { (Carbo) }\end{array}$ \\
\hline $25 \mathrm{mg}$ vials & 4.02 & 0 & 3.25 & 9.41 \\
\hline $10 \mathrm{mg}$ vials & 4.02 & 0 & 3.25 & 6.44 \\
\hline \multicolumn{5}{|l|}{ Novel agent (vials required per patient) } \\
\hline $1000 \mathrm{mg}$ vials & 16.08 & 0 & 0 & 137.75 \\
\hline $200 \mathrm{mg}$ vials & 16.08 & 0 & 0 & 28.58 \\
\hline $100 \mathrm{mg}$ vials & 0 & 16.92 & 0 & 276.77 \\
\hline $50 \mathrm{mg}$ vials & 0 & 0 & 13.0 & 94.92 \\
\hline $30 \mathrm{mg}$ vials & 0 & 4.23 & 0 & 131.34 \\
\hline
\end{tabular}

a Dialysis cost per 9.73 months (mean survival time across treatment arms).

(Table 4). It is clear that the major cost driver in the treatment of NSCLC is chemotherapy acquisition costs and that other resource use in the trial generally did not have a significant impact on the conclusions. The largest effect on costs was produced by varying the hospitalisation rates for the adverse events: total treatment costs per patient varied from $€ 6134$ to $€ 9688$ (Gem/Cis), from
$€ 8765$ to $€ 11,538$ (Pac/Carbo), and from $€ 5197$ to $€ 9341$ (Vin/Cis). Changes to hospitalisation costs also affected costs for Vin/Cis, which ranged from $€ 8866$ to $€ 9773$ per patient, but had little effect on Pac/Carbo costs $(€ 10,932$ to $€ 11,475$ per patient) or Gem/Cis costs ( $€ 7862$ to $€ 8326$ per patient). Similarly, changes in the costs of concomitant medications had a clear impact on Pac/Carbo 


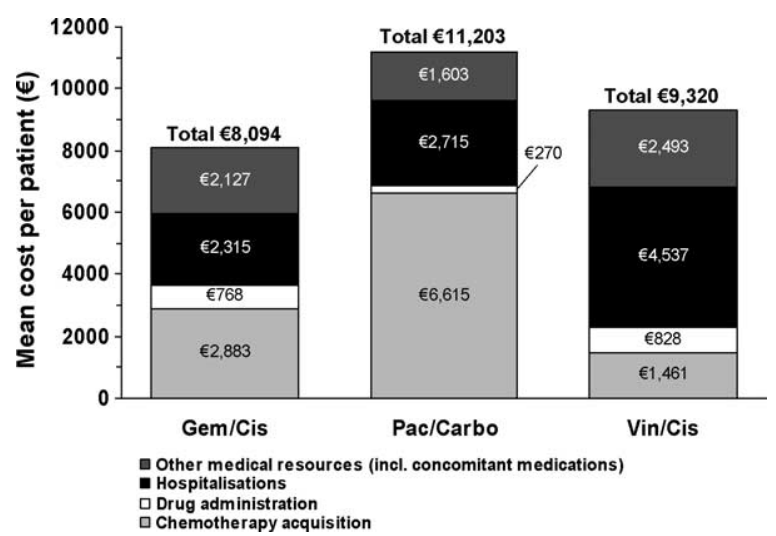

Fig. 1 Mean treatment-related costs per patient for each treatment group.

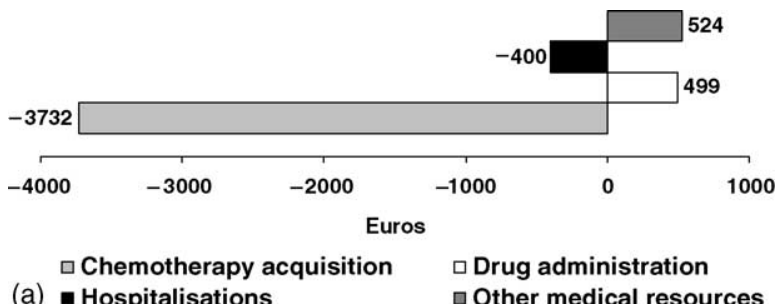

(a) - Hospitalisations

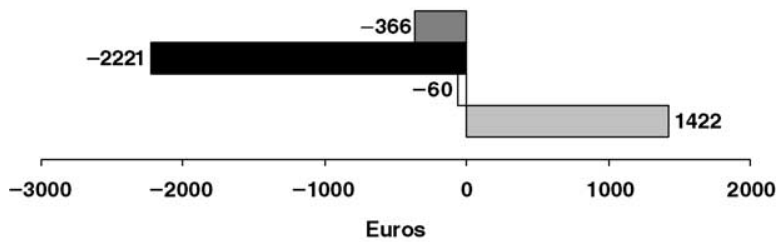

$\square$ Chemotherapy acquisition $\square$ Drug administration

(b) Hospitalisations

$\square$ Other medical resources

Fig. 2 Differences in cost $(€)$ per patient between (a) Gem/Cis and Pac/Carbo and (b) Gem/Cis and Vin/Cis treatment groups, by medical resource. results $(€ 10,448$ to $€ 11,958$ per patient) but little effect on the other treatment groups.

\section{Discussion}

Cost-minimisation analysis compares the costs of different treatment options under the assumption that the clinical outcome of the compared treatments or interventions is equivalent. It therefore focuses on comparing the cost of the treatment only, not the outcomes. Using this form of analysis, the treatment of choice is the option with the lowest overall cost. In the randomised trial in advanced NSCLC patients by Scagliotti et al. [9], there were no statistically significant differences between the three treatments (Gem/Cis, Pac/Carbo, Vin/Cis) in terms of progression-free or overall survival. Therefore, cost-minimisation was the appropriate form of economic evaluation. However, it should be noted that in the trial performed by Scagliotti et al. [9] there were some statistically significant differences between regimens with regard to qualityof-life endpoints. These differences raise the possibility of performing a cost-utility analysis using the study data. However, a cost-utility analysis was considered beyond the scope of the current analysis and was not performed as part of the present study.

The results of this retrospective economic analysis show that Gem/Cis was associated with lower total treatment costs than Pac/Carbo and Vin/Cis in the treatment of advanced NSCLC in Italy. Although the cost of chemotherapy was a major driver of the overall treatment costs for these platinum-based combination regimens, the costs of hospitalisations and other medical resources were also important

Table 4 Sensitivity analysis of mean total treatment costs for the three treatment groups

\begin{tabular}{|c|c|c|c|}
\hline \multirow[t]{2}{*}{ Sensitivity analysis } & \multirow{2}{*}{$\begin{array}{l}\text { Mean total } \\
\text { treatment costs }(€) \\
\text { Gem/Cis }\end{array}$} & \multicolumn{2}{|c|}{ Mean and incremental total treatment costs $(€)$} \\
\hline & & $\begin{array}{l}\text { Pac/Carbo (difference } \\
\text { from Gem/Cis) }\end{array}$ & $\begin{array}{l}\text { Vin/Cis (difference } \\
\text { from Gem/Cis) }\end{array}$ \\
\hline Base case & 8094 & $11,203(+3109)$ & $9320(+1226)$ \\
\hline Hospitalisation rates (all 100\%) & 9688 & $11,538(+1850)$ & $9341(-347)$ \\
\hline Hospitalisation rates (all 9\%) & 6134 & $8765(+2631)$ & $5197(-937)$ \\
\hline Hospitalisation costs $+10 \%$ & 8326 & $11,475(+3149)$ & $9773(+1447)$ \\
\hline Hospitalisation costs $-10 \%$ & 7862 & $10,932(+3070)$ & $8866(+1004)$ \\
\hline Cisplatin administered on day 1 of cycle & 7838 & $11,203(+3365)$ & $9320(+1482)$ \\
\hline Drug admin costs $+10 \%$ & 8171 & $11,230(+3059)$ & $9403(+1232)$ \\
\hline Drug admin costs $-10 \%$ & 8017 & $11,176(+3159)$ & $9237(+1220)$ \\
\hline Concomitant meds costs $+10 \%$ & 8527 & $11,958(+3431)$ & $9647(+1120)$ \\
\hline Concomitant meds costs $-10 \%$ & 7661 & $10,448(+2787)$ & $8992(+1331)$ \\
\hline Other resource costs $+10 \%$ & 8162 & $11,270(+3108)$ & $9388(+1226)$ \\
\hline Other resource costs $-10 \%$ & 8026 & $11,136(+3110)$ & $9252(+1226)$ \\
\hline
\end{tabular}


factors. The chemotherapy acquisition costs were highest for Pac/Carbo and accounted for 59\% of the total costs per patient. In comparison, chemotherapy acquisition accounted for $36 \%$ of the total costs of the Gem/Cis regimen and for only $16 \%$ of the total costs of the Vin/Cis regimen.

Our findings agree with previous economic evaluations in advanced NSCLC. In a recent retrospective cost-minimisation analysis of two randomised trials $[8,10]$, Schiller et al. [24] found that Gem/Cis was associated with lower treatment-related costs than Vin/Cis, $\mathrm{Pac} / \mathrm{Cis}$ or Pac/Carbo in five European countries (France, Germany, Italy, Spain, UK). Another retrospective analysis using published clinical trial data showed that $\mathrm{Gem} / \mathrm{C}$ is was associated with lower total treatment costs than $\mathrm{Vin} / \mathrm{Cis}$ or Pac/Carbo [18]. In the latter analysis, the reduced costs with $\mathrm{Gem} / \mathrm{C}$ is were due to lower chemotherapy administration costs compared with $\mathrm{Vin} / \mathrm{C}$ is and lower chemotherapy drug costs compared with Pac/Carbo.

In our analysis, all chemotherapy was administered on an outpatient basis; the chemotherapy administration costs were comparable between the $\mathrm{Gem} / \mathrm{C}$ is and $\mathrm{Vin} / \mathrm{C}$ is regimens and lower for the $\mathrm{Pac} / \mathrm{Carbo}$ regimen. The main cost difference between the two cisplatin-based regimens was due to the lower costs for hospitalisation associated with adverse events in the $\mathrm{Gem} / \mathrm{C}$ is group. Previous studies have also indicated that the higher drug acquisition costs of gemcitabine regimens can be offset by a decrease in hospitalisation costs [25].

In our analysis, Pac/Carbo was more expensive in terms of total resource costs than either $\mathrm{Gem} / \mathrm{Cis}$ or Vin/Cis. This is consistent with a recent economic analysis of the large Southwest Oncology Group (SWOG) trial, which reported that Pac/Carbo was significantly more expensive than $\mathrm{Vin} / \mathrm{C}$ is in patients with advanced NSCLC [26]. The major cost difference was due to the high acquisition costs of chemotherapy drugs in the Pac/Carbo regimen, which were not offset by lower costs elsewhere (such as for hospitalisations due to adverse events). Schiller et al. [24] also found that the main cost difference between Gem/Cis and Pac/Carbo was due to the higher acquisition costs of chemotherapy associated with Pac/Carbo in all five European countries studied. Indeed, Ramsey et al. [26] warned that widespread use of Pac/Carbo rather than Vin/Cis would substantially increase national expenditures for the treatment of advanced lung cancer.

Although the chemotherapy acquisition costs were much lower for the Vin/Cis regimen than the $\mathrm{Gem} / \mathrm{Cis}$ and $\mathrm{Pac} /$ Carbo regimens, the costs for outpatient administration of the chemotherapy were highest for this treatment group. This agrees with both economic analyses based on the clinical trial by Comella et al. [10], which found that $\mathrm{Gem} / \mathrm{C}$ is was associated with a lower total cost relative to $\mathrm{Vin} / \mathrm{C}$ is due to the higher administration costs of the latter regimen $[18,24]$. The analysis by Lees et al. [18] made assumptions that the use of resources such as hospitalisation, transfusion and concomitant medication would be identical in the two treatment groups. These assumptions may not be valid, however, since our analysis based on the clinical trial published by Scagliotti et al. [9] found that Vin/Cis treatment incurred higher costs associated with hospitalisation and other medical resources than either Gem/Cis or Pac/Carbo. In addition, Schiller et al. [24] found that hospitalisations provided the largest cost saving between the Gem/Cis and Vin/Cis regimens in France, Germany and Italy. Moreover, although not a consistent finding [27], some previous studies have found that $\mathrm{Vin} / \mathrm{C}$ is regimens are associated with higher toxicity and worse tolerability than Gem/Cis [10] or Pac/Carbo [17]. It must be noted that the chemotherapeutic regimens used in different clinical studies often vary in terms of dosages or mean cycle length. Both factors can have a large impact on overall treatment costs, making it difficult to compare cost results across studies.

The present study has some inevitable limitations. First, the resource utilisation data on which the analysis is based were to a certain extent protocol-driven. Although this is a recommended method for pharmacoeconomic assessment $[28,29]$, the resource use may not accurately reflect real clinical practice. The analysis excluded protocoldriven costs where possible and focused on the main cost components. However, as patients in clinical trials are likely to be closely monitored and observed, the resource use is probably overestimated in this analysis. Second, direct non-medical costs (such as those associated with domestic help and home nursing and costs incurred by patients travelling to the clinic/hospital) and the indirect costs of lost productivity were not considered in the analysis since the study perspective was that of the national healthcare provider and it was therefore considered inappropriate to include these costs.

In contrast to many previous economic evaluations, the present analysis used outcome and resource utilisation data collected prospectively from the same source, thereby limiting selection bias. However, not all the resources documented in the clinical trial database were costed. As every drug for each patient was specifically documented, we would have had to look up the cost for hundreds 
of individual drugs, many of which are similar in price. For the sake of simplicity, only the most frequently used concomitant medication or very expensive medication was costed and included in the analysis. Second-line chemotherapy and radiotherapy were not costed in the present analysis, although they were documented by Scagliotti et al. [9]. The requirements for second-line chemotherapy or radiotherapy appeared to be fairly well balanced between treatment groups [9], but no statistical analysis was performed on these data. It is possible, therefore, that the costs relating to second-line chemotherapy or radiotherapy may have influenced the results of the present analysis had they been included.

\section{Conclusion}

This retrospective cost-minimisation analysis has shown that Gem/Cis is associated with lower mean total costs than Pac/Carbo or Vin/Cis when used as first-line treatment for NSCLC. For decision makers with a limited budget, the $\mathrm{Gem} / \mathrm{C}$ is regimen therefore represents an efficient use of resources for patients with advanced NSCLC in Italy.

\section{Acknowledgements}

This study was supported by Eli Lilly and Company. The authors would like to thank Deirdre Elmhirst for her help in preparing the manuscript.

\section{References}

[1] Mather D, Sullivan SD, Parasuraman TV. Beyond survival: economic analyses of chemotherapy in advanced inoperable NSCLC. Oncology (Huntingt) 1998;12:199-209.

[2] Hoffman PC, Mauer AM, Vokes EE. Lung cancer. Lancet 2000;355:479-85.

[3] Ettinger DS. Is there a preferred combination chemotherapy regimen for metastatic non-small cell lung cancer? Oncologist 2002;7:226-33.

[4] Parkin DM, Pisani P, Ferlay J. Global Cancer Statistics. CA Cancer J Clin 1999;49:33-64.

[5] Szczepura A. Healthcare outcomes: gemcitabine costeffectiveness in the treatment of non-small cell lung cancer. Lung Cancer 2002;38:S21-8.

[6] Non-small Cell Lung Cancer Collaborative Group. Chemotherapy in non-small cell lung cancer: a meta-analysis using updated data on individual patients from 52 randomised clinical trials. Br Med J 1995;311:899-909.

[7] Clegg A, Scott DA, Hewitson P, Sidhu M, Waugh N. Clinical and cost-effectiveness of paclitaxel, docetaxel, gemcitabine, and vinorelbine in non-small cell lung cancer: a systematic review. Thorax 2002;57:20-8.
[8] Schiller JH, Harrington D, Belani CP, Langer C, Sandler A, Krook J, et al. Comparison of four chemotherapy regimens for advanced non-small-cell lung cancer. N Engl J Med 2002;346:92-8 (for the Eastern Cooperative Oncology Group).

[9] Scagliotti GV, De Marinis F, Rinaldi M, Crino L, Gridelli C, Ricci S, et al. Phase III randomized trial comparing three platinum-based doublets in advanced non-small-cell lung cancer. J Clin Oncol 2002;20:4285-91 (for the Italian Lung Cancer Project).

[10] Comella P, Frasci G, Panza N, Manzione L, De Cataldis $G$, Cioffi R, et al. Randomised trial comparing cisplatin, gemcitabine, and vinorelbine with either cisplatin and gemcitabine or cisplatin and vinorelbine in advanced nonsmall cell lung cancer: interim analysis of a phase III trial of the Southern Italy Cooperative Oncology Group. J Clin Oncol 2000;18:1451-7.

[11] Sandler AB, Nemunaitis J, Denham C, von Pawel J, Cormier Y, Gatzemeier U, et al. Phase III trial of gemcitabine plus cisplatin vs. cisplatin alone in patients with locally advanced or metastatic non-small cell lung cancer. J Clin Oncol 2000;18:122-30.

[12] Sederholm C. Gemcitabine vs. gemcitabine/carboplatin in advanced non-small-cell lung cancer: preliminary findings in a phase III trial of the Swedish Lung Cancer Study Group. Semin Oncol 2002;29(3 Suppl. 9):50-4.

[13] Kosmidis P, Mylonakis N, Nicolaides C, Kalophonos C, Samantas E, Boukovinas J, et al. Paclitaxel plus carboplatin vs. gemcitabine plus paclitaxel in advanced non-small cell lung cancer: a phase III randomized trial. J Clin Oncol 2002;20:3578-85.

[14] Bonomi P, Kim K, Fairclough D, Cella D, Kugler J, Rowinsky E, et al. Comparison of survival and quality of life in advanced non-small cell lung cancer patients treated with two dose levels of paclitaxel combined with cisplatin vs. etoposide with cisplatin: results of an Eastern Cooperative Oncology Group trial. J Clin Oncol 2000;18:623-31.

[15] Wozniak AJ, Crowley JJ, Balcerzak SP, Weiss GR, Spiridonidis $\mathrm{CH}$, Baker $\mathrm{LH}$, et al. Randomized trial comparing cisplatin with cisplatin plus vinorelbine in the treatment of advanced non-small cell lung cancer: a Southwest Oncology Group Study. J Clin Oncol 1998;16:2459-65.

[16] Van Meerbeeck JP, Smit E, Lianes P, Schramel F, Lenz M, Debruyne C, et al. A EORTC randomized phase III trial of three chemotherapy regimens in advanced non-small cell lung cancer (NSCLC). Proc Am Soc Clin Oncol 2001;20:308a (for the Italian Lung Cancer Project).

[17] Kelly K, Crowley J, Bunn Jr PA, Presant CA, Grevstad PK, Moinpour CM, et al. Randomised phase III trial of paclitaxel plus carboplatin vs. vinorelbine plus cisplatin in the treatment of patients with advanced non-small cell lung cancer. A Southwest Oncology Group trial. J Clin Oncol 2001;19:3210-8.

[18] Lees M, Aristides M, Maniadakis N, McKendrick J, Botwood $\mathrm{N}$, Stephenson D. Economic evaluation of gemcitabine alone or in combination with cisplatin in the treatment of nonsmall cell lung cancer. Pharmacoeconomics 2002;20:325-37.

[19] Sources of unit costs of medical resources in Italy. Available from http: / /www.federfarma.it.

[20] Ministero della Sanità (Italian Ministry of Health). Official negotiated prices of certain medications. Available from http://www.ministerosalute.it/medicinali.

[21] Tediosi F, Bertolini G, Parazzini F, Mecca G, Garattini L. Cost analysis of dialysis modalities in Italy. Health Serv Manage Res 2001;14:9-17.

[22] Lucioni C, Garancini MP, Massi-Benedetti M, Mazzi S, Serra $\mathrm{G}$, on behalf of the Advisory Italian Board of the CODE-2 
study. Social costs of diabetes type II in Italy: CODE-2 study. Pharmacoeconomics Italian Res Articles 2000;2:1-21.

[23] Lucioni C, Ravasio R, Concia E. Terapia empirica con antibiotici parenterali in pazienti ospedalizzati affetti da infezioni alle basse vie respiratorie: una valutazione farmacoeconomica. Pharmacoeconomics Italian Res Articles 2001;3:37-47.

[24] Schiller J, Tilden D, Aristides M, Lees M, Kielhorn A, Maniadakis $\mathrm{N}$, et al. Retrospective cost analysis of gemcitabine in combination with cisplatin in non-small cell lung cancer compared to other combination therapies. Lung Cancer 2004;43:101-12.

[25] Sacristan JA, Kennedy-Martin T, Rosell R, Cardenal F, Anton $A$, Lomas $M$, et al. Economic evaluation in a randomized phase III clinical trial comparing gemcitabine/cisplatin and etoposide/cisplatin in non-small cell lung cancer. Lung Cancer 2000;28:97-107.

[26] Ramsey SD, Moinpour CM, Lovato LC, Crowley JJ, Grevstad $\mathrm{P}$, Presant CA, et al. Economic analysis of vinorelbine plus cisplatin vs. paclitaxel plus carboplatin for advanced nonsmall-cell lung cancer. J Natl Cancer Inst 2002;94:291-7.

[27] Moinpour CM, Lyons B, Grevstad PK, Lovato LC, Crowley J, Czaplicki K, et al. Quality of life in advanced non-smallcell lung cancer: results of a Southwest Oncology Group randomized trial. Qual Life Res 2002;11:115-26.

[28] American Society of Clinical Oncology. Outcomes of cancer treatment for technology assessment and cancer treatment guidelines. J Clin Oncol 1996;14:671-9.

[29] Earle CC, Coyle D, Evans WK. Cost-effectiveness analysis in oncology. Annu Oncol 1998;9:475-82.

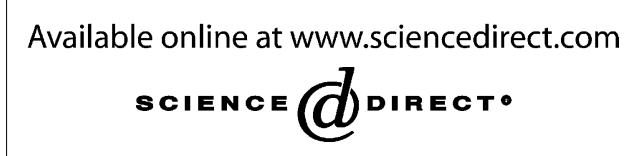

